\title{
Observatorio Inmobiliario
}

CIUDAD Y TERRITORIO

ESTUDIOS TERRITORIALES

ISSN(P): 1133-4762; ISSN(E): 2659-3254

Vol. LIII, № 207, primavera 2021

Págs. $215-228$

https://doi.org/10.37230/CyTET.2021.207.13

CC BY-NC-ND

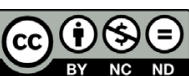

\section{Un ejercicio difícil para el mercado de vivienda}

Julio RodRíGuez-López

Vocal del Consejo Superior de Estadística del INE

“Para la mayoría de los arrendatarios del Reino Unido (condicionados por las perspectivas de alquileres crecientes, pobres condiciones de vida y la amenaza en curso de un desahucio) la idea de recibir una carta del propietario arrendador de la vivienda indicándoles la reducción de la renta mensual podría ser algo por completo impensable"

Alexander Vasudevan, "Berlin "rent cap offers a new way of thinking about Britain's Housing crisis” The Guardian, 25.11.2020.

\section{Introducción}

2020 ha sido un año marcado de forma decisiva por la aparición de un brote generalizado del coronavirus Covid 19. En el presente trabajo se describe en el primer apartado la incidencia que dicha circunstancia ha ejercido sobre el conjunto de la economía mundial. En el segundo apartado se resume la incidencia que sobre la economía española ejerció el conjunto de confinamientos derivados de la aparición del brote desde marzo de 2020. En el apartado tercero se resume la desaceleración experimentada por los niveles de precios de la vivienda y de los alquileres, evolución que reflejan de forma diferenciada los distintos indicadores disponibles. Todo apunta a que los precios citados habrán terminado 2020 en niveles inferiores a los alcanzados en el primer trimestre del año.

En el cuarto apartado se resume la evolución de la demanda, en la que todo indica que el número de ventas de viviendas puede ser inferior en un $20 \%$ a los niveles de 2019 . El quinto apartado recoge los descensos que los confinamientos han ocasionado en el ritmo de construcción y de iniciación de viviendas, subrayando como las ventas de viviendas nuevas son inferiores a las viviendas terminadas en este año, evolución que no se producía desde 2012. El sexto y último apartado resume las principales modificaciones aparecidas en materia de política de vivienda, entre las que destaca la extensión a 2022 del Plan Estatal de Vivienda 2018-21 y el fuerte aumento de las partidas de

Julio Rodriguez López es doctor en CC. Económicas. Ha sido presidente del Banco Hipotecario de España y de Caja Granada. Correo electrónico: julio.r.lopez@pataura.e.telefonica.net 
gasto publico destinados a vivienda, en especial las ligadas a la rehabilitación.

\section{Las experiencias de 2020 y las previsiones tras los procesos de confinamiento}

El momento más difícil para la economía mundial como consecuencia de la pandemia de la Covid 19 en 2020 se produjo en el mes de abril, al que sucedió una recuperación moderada en los meses de mayo y junio. A pesar de esto último el resultado global fue de un descenso acusado de la actividad y del empleo en el segundo trimestre del año. Tras una clara recuperación en el tercer trimestre, los rebrotes de la pandemia producidos a partir del verano han contribuido a frenar la senda de recuperación. De este modo en el último trimestre del año han podido producirse nuevos descensos del nivel de actividad, que pueden acentuar el retroceso de la actividad global en 2020 (OCDE, 2020).

En 2020 se ha puesto de manifiesto la seria dificultad para subsistir de numerosas empresas, que han precisado de importantes ayudas para mantener la actividad. Las dificultades han sido mayores en general en el sector de los servicios, especialmente en los subsectores del turismo y de los viajes aéreos. La vacunación intensa prevista para 2021 ayudará a recobrar una mayor confianza y a una recuperación gradual de la actividad en los años posteriores. A fines de 2021 podrían alcanzarse niveles de actividad equivalentes a los anteriores a la crisis, aunque en numerosos países todavía persistirán durante 2022 niveles inferiores a los de la etapa prepandemia.

De acuerdo con las previsiones del Fondo Monetario Internacional (FMI, 2020) el PIB mundial, tras crecer a un ritmo del 2,8\% en 2018, habrá retrocedido en un $4,4 \%$ en 2020 , mientras que en 2021 puede tener lugar una recuperación del $5,2 \%$ en 2021. El descenso de la actividad en 2020 va a ser superior en los países de economías avanzadas $(-5,8 \%)$ respecto de los países de economías emergentes (-3,3\%) (FIG. 1). El comercio mundial habrá descendido en un $10,4 \%$ en 2020 , previéndose una recuperación del mismo de un 8,3\% en 2021 (FMI, op. cit.)

La realidad de unos procesos de vacunación intensivos en 2021 puede aumentar la confianza general y rebajar las necesidades de ahorro precautorio. Esta evolución puede animar la demanda de consumo y permitir recuperaciones más acusadas de la economía, que se dejarán sentir sobre todo en 2022. La intensidad que parece presentar el nuevo rebrote de la pandemia en el último mes de 2020 puede generar nuevos retrocesos de la actividad. De este modo el retorno hasta los

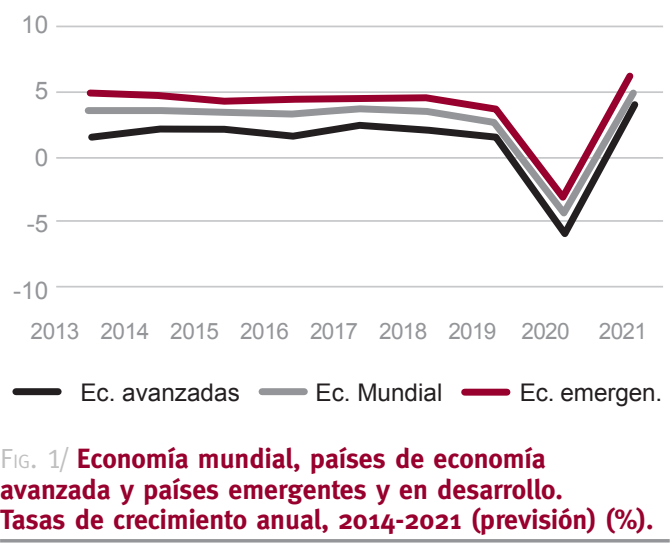

Fuente: FMI.

niveles previos a la pandemia puede sufrir un nuevo retroceso.

Los procesos de confinamiento asociados con la pandemia del coronavirus Covid 19 puede revertir buena parte de los logros conseguidos después de 1990. Esta evolución acentuará las desigualdades y los niveles de pobreza. La política monetaria desarrollada por los bancos centrales, basada en la adquisición masiva de deuda pública y de bonos, se ha convertido en una auténtica barrera que está permitiendo mantener mayores niveles de actividad. Los tipos de interés continúan situados en niveles reducidos, presentando un nivel negativo el Euribor a doce meses. La pandemia está asociada con los mayores aumentos de deuda pública registrados en 2020 después de la última guerra mundial.

Aunque la vacunación masiva prevista para 2021 puede generar una mejoría sustancial de las previsiones, los errores desarrollados en las primeras etapas de aparición de la pandemia generarán consecuencias negativas durante cierto tiempo. Los aumentos de las desigualdades y de la pobreza han sido espectaculares en Estados Unidos, mientras que las ayudas a las empresas y a los autónomos han impedido que la crisis social alcanzase un nivel similar en Europa.

En el periodo 2021-22 Europa vivirá bajo la sombra de la deflación (A. Touze, 2020). El mayor volumen de la deuda tendrá carácter interno, esto es, el principal acreedor será el respectivo banco central. El aumento del endeudamiento general, del déficit público y de la deuda pública llevará a replantearse la conveniencia o no de desarrollar políticas estabilizadoras. Deberá impedirse la repetición de los errores cometidos durante la crisis precedente de 2008-2011, de forma que sea posible ayudar a los sectores más necesitados, así como también llevar a cabo las inversiones asociadas con la transición energética necesaria para la descarbonización de las economías. 


\section{La incidencia negativa de la pandemia sobre la economía española}

La economía española registro una etapa de crecimiento continuado entre 2014 y 2019 , en cuya evolución el positivo comportamiento de las exportaciones desempeñó un papel importante. La aparición de un intenso brote del coronavirus Covid 19 en marzo de 2020 dio lugar a procesos de confinamiento obligatorio. Esta circunstancia contribuyó a reducir la actividad y el empleo, en especial en el turismo y otros servicios, que tienen un peso mayor en España que en el resto de países de la Eurozona.

EI PIB de la economía española presentó variaciones trimestrales negativas en los dos primeros trimestres del año. Los descensos de actividad tuvieron una especial intensidad en el segundo trimestre de 2020. En este periodo fueron notables los retrocesos trimestrales que tuvieron lugar en la inversión en bienes de equipo $(-29,9 \%)$, construcción (-22,5\%). Destacaron sobre todo los descensos asociados con el comercio internacional. Las exportaciones disminuyeron en un $33,4 \%$, por encima de la caída de las importaciones $(-29,5 \%)$.

A pesar de la fuerte recuperación de la actividad en el tercer trimestre de 2020 , el nivel del PIB en dicho periodo era inferior en un $9 \%$ al correspondiente al cuarto trimestre de 2019. En el conjunto de los tres primeros trimestres de 2020 el PIB de la economía española descendió en un $11,5 \%$ respecto del mismo periodo de 2019 (FIG. 2). La

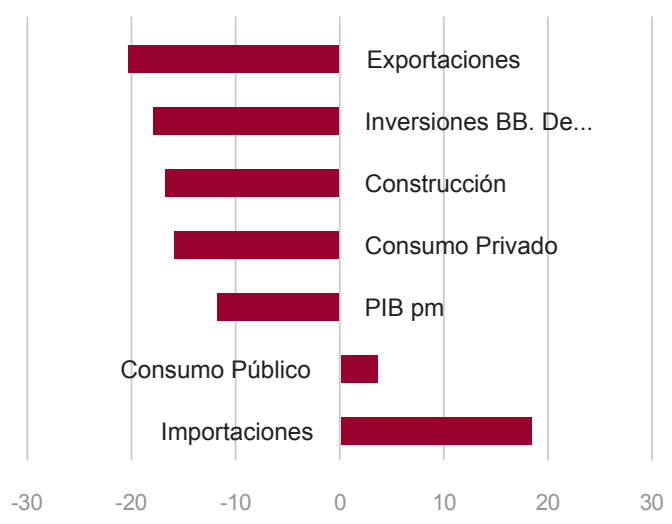

Economía española. Principales agregados macroeconómicos. Tasas de variación 2020/2019 (\%), tres primeros trimestres.

Fuente: INE.

demanda interna retrocedió en un $10,5 \%$, lo que indica que la aportación del resto del mundo fue negativa en este periodo, reflejo de la amplitud internacional de la crisis de actividad y de empleo.

La aparición de nuevos rebrotes del coronavirus desde septiembre frenó la intensidad del proceso de recuperación de la actividad perdida en la primera "ola" del Covid 19. Esta evolución ha llevado a que diferentes organismos internacionales hayan establecido previsiones muy negativas respecto de la evolución de la economía española en 2020.

Las previsiones del consenso de Funcas sitúan dicha variación en un retroceso del PIB en un 11,8\% (FIG. 3). La demanda interna descenderá

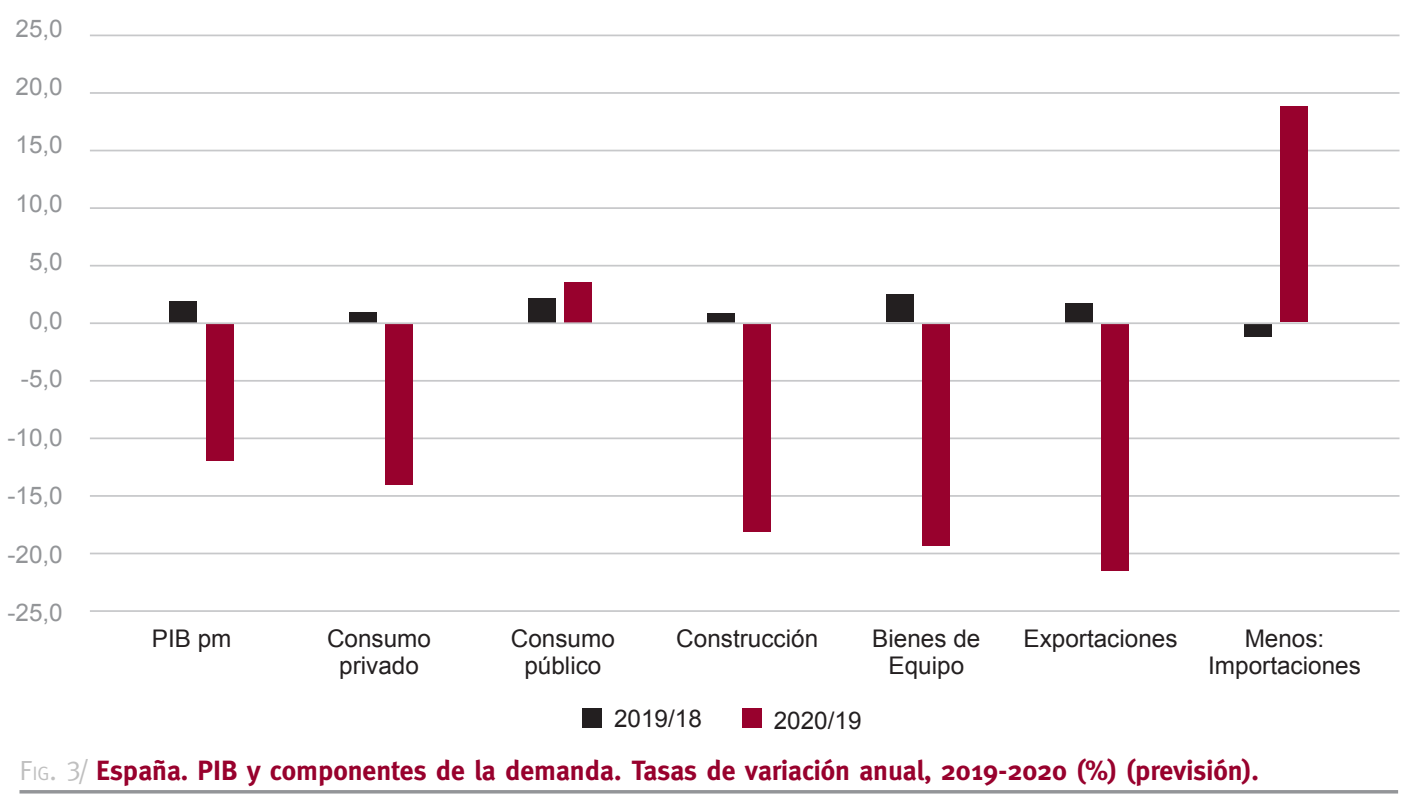

Fuente: INE y FunCAS 
un 10,6\% según dicha previsión, y la aportación neta del resto del mundo se aproximará un punto porcentual negativo. La previsión del FMI de octubre de 2020 anticipó para España un retroceso del $12,8 \%$ mientras que la OCDE, en su informe semestral aparecido en diciembre de 2020 , ha situado el descenso en cuestión en un 11,6\%. Dicho descenso supera la previsión correspondiente al conjunto de la Eurozona, el $-7,5 \%$ según el FMI y la OCDE.

La contracción de la actividad ha afectado de forma negativa a la evolución del empleo. Según la Encuesta de Población Activa del INE, los ocupados disminuyeron en los dos primeros trimestres del año, destacando la caída del empleo en un $6,7 \%$ en el segundo trimestre, según la serie trimestral corregida de variación estacional.

La tasa de desempleo, que se situó en el $14,1 \%$ en 2019 , aumentó hasta un 16,3\% de la población activa en el tercer trimestre de 2020 . En este periodo el empleo se redujo en un $3,5 \%$ respecto de 2019, descenso correspondiente a una disminución anual de los ocupados en 697.500. El número de afiliados a la Seguridad Social retrocedió en noviembre de 2020 en un 2,3\% sobre el mismo mes del año anterior, correspondiendo dicha variación relativa a una disminución absoluta de los afiliados en 440.800 (FIG. 4).

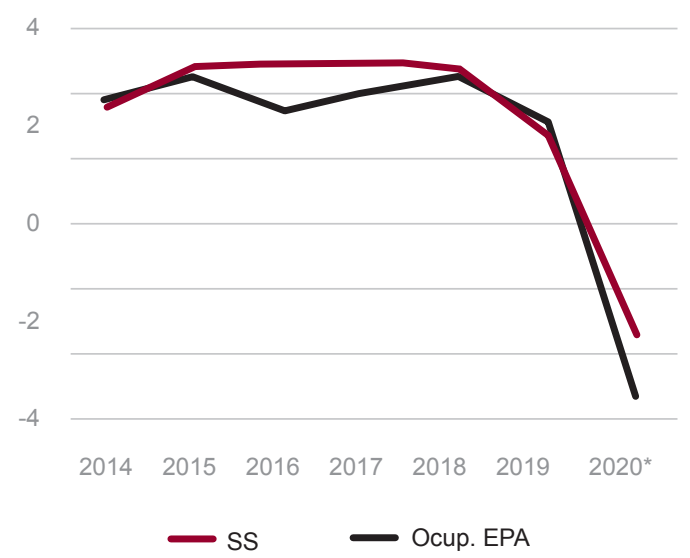

Empleo. Ocupados EPA y Afiliados a la S. Social. Tasas de variación interanual (\%). Datos a fin de año, 2014-2020 (previsión).

Fuente: INE y MINISTERIO de INCLUSIÓN Y SEGURIDAd SOCIAL.

El índice de precios de consumo disminuyó en un $0,8 \%$ en noviembre de 2020 sobre igual periodo de 2019. La inflación subyacente (productos no alimenticos y no energéticos), creció en un $0,7 \%$ en el mismo periodo de tiempo. Los productos alimenticios han crecido, destacando el $2 \%$ de variación anual registrada por los alimentos no elaborados, mientras que los productos energéticos han disminuido en noviembre en un $9,5 \%$. El saldo positivo de la balanza de pagos por cuenta corriente, que se elevó al $1,6 \%$ del PIB en 2019 , se ha previsto por Funcas que descienda hasta el 0,6\% en 2020.

En 2020 destaca la previsible aprobación de unos Presupuestos Generales del Estado para 2021 en los que el gasto publico crecerá en un $17,5 \%$, aumento que se cubrirá con un déficit mayor, cuyo nivel relativo ascenderá al $12,4 \%$ del PIB, mientras que la deuda publica pasará desde el 96,9\% del PIB en 2019 hasta el 116\% en 2020. El Estado y el sector privado podrán obtener financiación en los mercados de capitales en condiciones muy favorables. De ese modo, el reto para 2021 será sobre todo el de emplear mejor las mayores disponibilidades de recursos (R. TORRES, 2020).

\section{Mercado de vivienda (I). Precios y alquileres}

Después del hundimiento de precios que sucedió al "pinchazo" de la burbuja inmobiliaria, el mercado de vivienda se recuperó en España a un ritmo moderado pero firme entre 2013 y 2019. Tras un cierto enfriamiento de dicho mercado en 2019, en 2020 la pandemia de la Covid 19, con su secuela de confinamientos, ha ejercido una poderosa influencia negativa. A unos descensos importantes en los dos primeros trimestres del año sucedió un aumento espectacular de los indicadores del mercado de vivienda en el tercer trimestre de 2020.

Pero dicha evolución tuvo carácter más bien de "rebote" que de recuperación. La marcha de los indicadores en el último trimestre del año parece indicar que la reactivación no ha tenido continuidad. 2020 habrá sido un ejercicio negativo para el mercado inmobiliario. Lo importante ahora es que la economía española se recupere de forma significativa en 2021 y que la política de vivienda contribuya a mejorar la accesibilidad a la vivienda en el próximo ejercicio.

El índice de precios de la vivienda del INE registró un aumento trimestral del $1,1 \%$ en el tercer trimestre de 2020 (0,1\% en el trimestre precedente). Dicho aumento se debió sobre todo al importante incremento registrado por los precios de la vivienda de nueva construcción (4,7\%). El aumento interanual de los precios de la vivienda fue el $1,7 \%$ en el tercer trimestre de 2020 sobre el mismo periodo del año precedente (FIG. 5). 


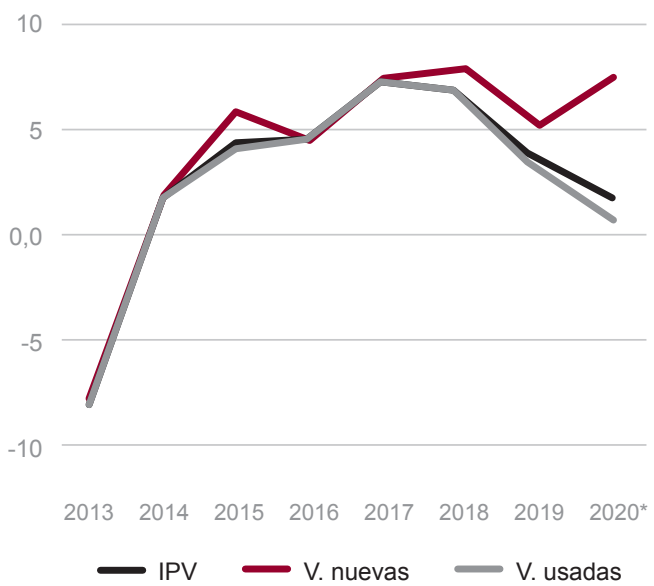

/ Índice de precios de vivienda. Total, nuevas y usadas. Tasas de variación anual, 2013-2020 (previsión) (\%).

Fuente: INE.
El crecimiento interanual de los precios de la vivienda nueva fue el $7,5 \%$, mientras que en el caso de la vivienda usada el crecimiento anual se redujo al $0,8 \%$. La escasez de la oferta de nuevas viviendas puede ser la variable que mejor explique el importante desnivel existente entre las variaciones de los precios de las viviendas de nueva construcción y las usadas. Así, en el tercer trimestre de 2020 , el valor medio de tasación ascendió a $1.899,4$ euros $/ \mathrm{m}^{2}$ para viviendas de hasta cinco años de antigüedad, mientras que dicho valor fue de $1.610,7$ euros $/ \mathrm{m}^{2}$ para las de más de cinco años. El valor de tasación medio de las viviendas de nueva construcción supera en casi un $18 \%$ al de las viviendas usadas.

Por comunidades autónomas el aumento interanual de los precios de la vivienda más elevado en el tercer trimestre de 2020 fue el de Baleares $(3,4 \%)$, seguido por Murcia (3\%). Las variaciones más modestas de los precios fueron las de la Comunidad de Madrid (1,2\%) y Extremadura (0\% (FIG. 6). El precio medio de venta de las viviendas

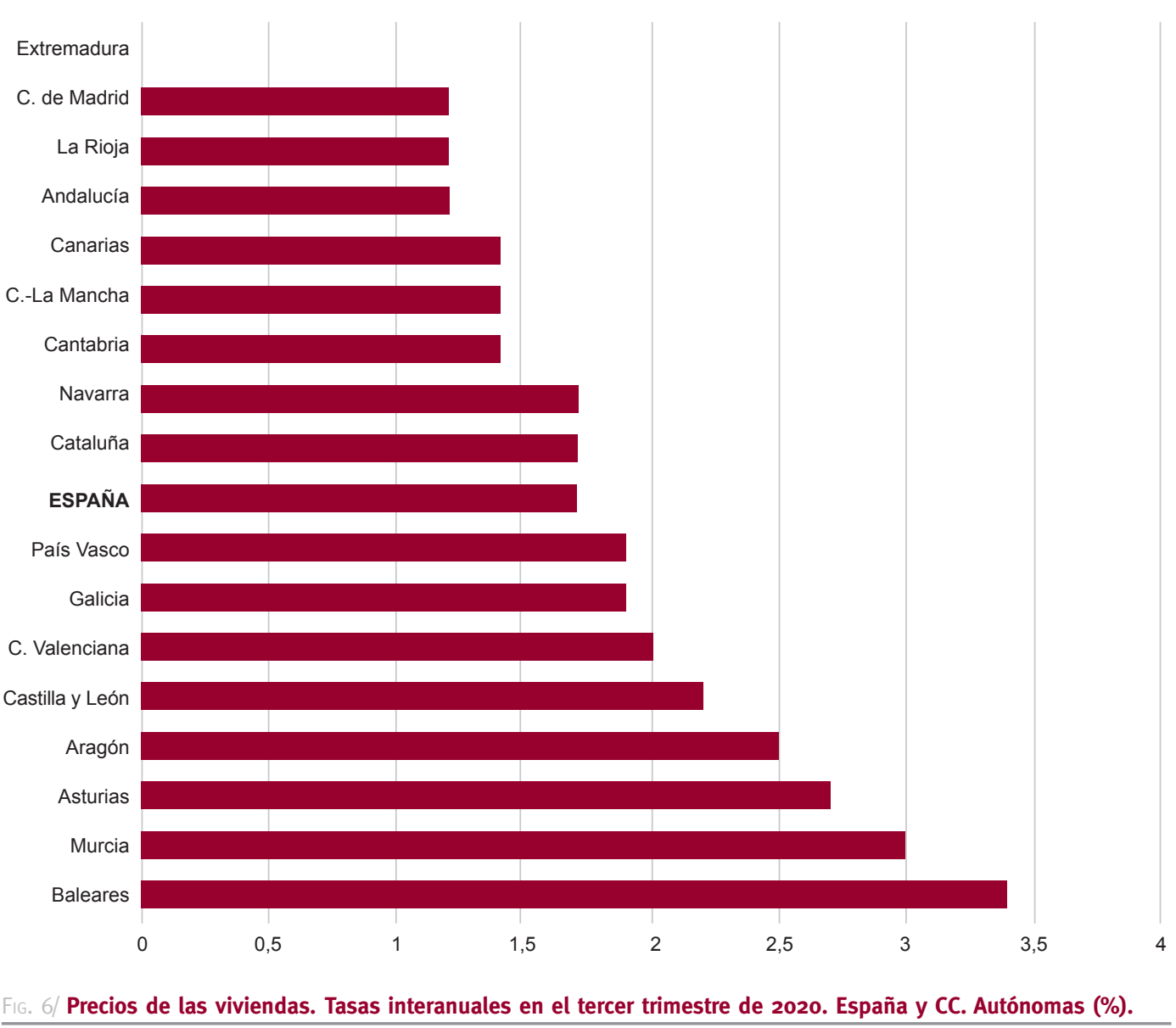

Fuente: INE. 
3500

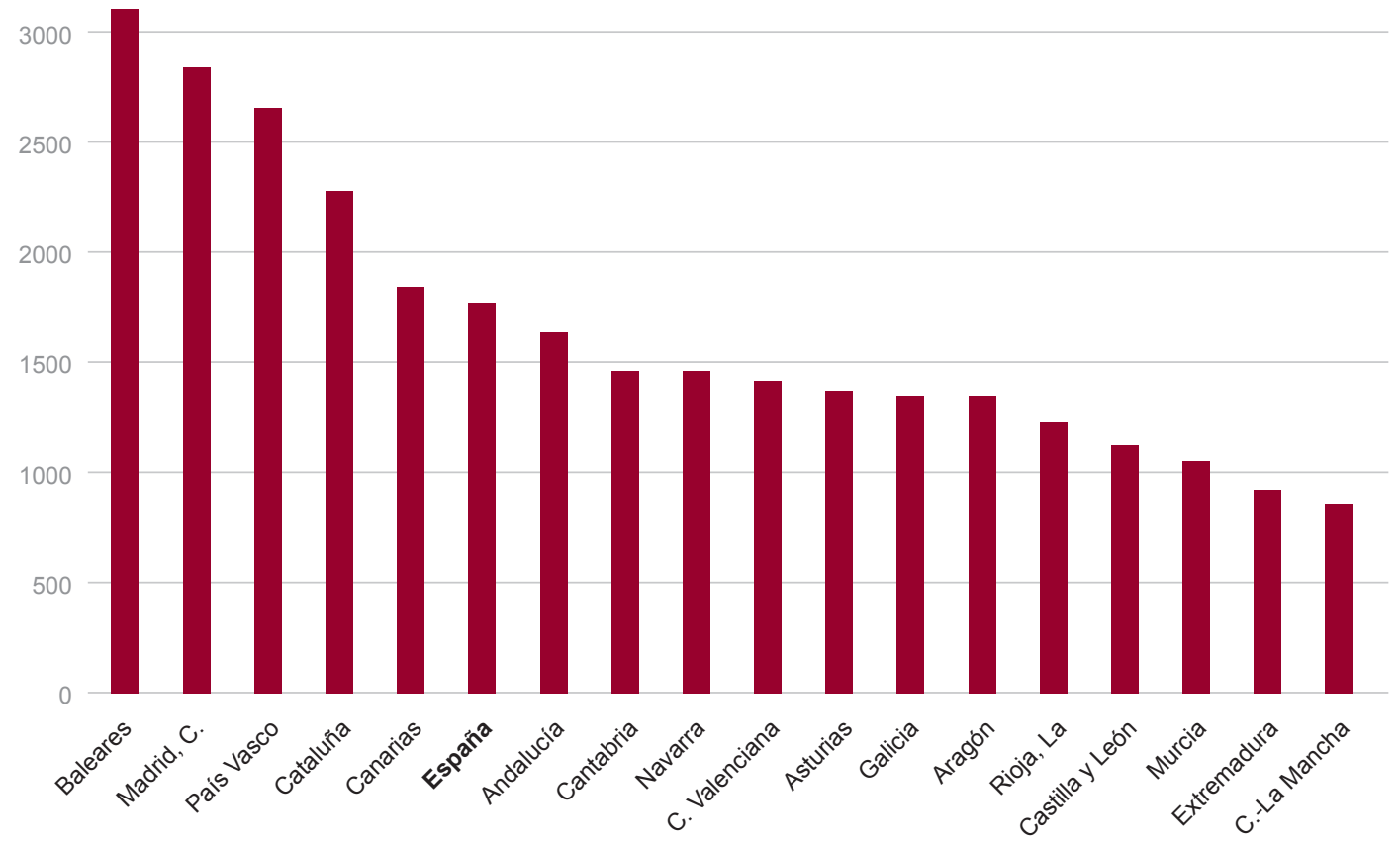

/ Precios de las viviendas, España y CC. Autónomas, tercer trimestre de 2020 euros $/ \mathrm{m}^{2}$.

según Idealista.com ascendió a 1.769 euros $/ \mathrm{m}^{2}$. Los precios de venta más elevados, según dicha fuente estadística, correspondieron a Baleares (3.103 euros $/ \mathrm{m}^{2}$ ) y a la Comunidad de Madrid (2.832 euros $\left./ \mathrm{m}^{2}\right)$. Las autonomías con precios de venta medios más reducidos fueron Extremadura (922 euros $/ \mathrm{m}^{2}$ ) y Castilla-La Mancha (856 euros/ $\mathrm{m}^{2}$ ) (FIG. 7). El aumento anual de los precios de venta de las viviendas según Idealista.com fue el $0,4 \%$ en noviembre de 2020 .

Tras los importantes aumentos registrados por los alquileres hasta 2019, la tendencia alcista se mantuvo más moderada en el primer trimestre de 2020. A partir de este periodo la evolución de los alquileres fue de estancamiento (FIG. 8), coincidiendo con la aparición del brote de corona virus en marzo de 2020. El nivel de los alquileres se situó en 11,2 euros $/ \mathrm{m}^{2}$-mes en noviembre de 2020, un 3,6\% por encima del mismo periodo de 2019. En dicho mes los niveles de alquileres más elevados correspondieron a la Comunidad de Madrid (14,5 euro/m²-mes), Cataluña (14 euros/ $\mathrm{m}^{2}$-mes). Los niveles medios más reducidos de alquileres en el mes citado fueron los de CastillaLa Mancha $\left(5,7\right.$ euros $/ \mathrm{m}^{2}$-mes) y Extremadura, con 5,3 euros $/ \mathrm{m}^{2}$-mes (FIG. 9).

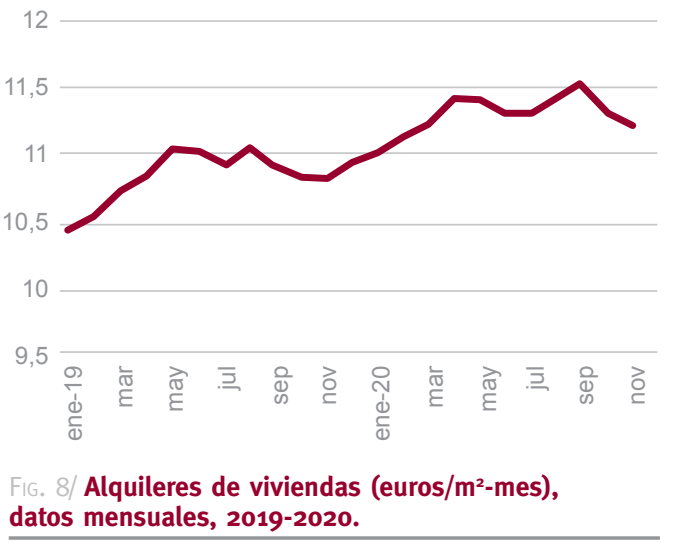

Fuente: Idealista.com.

La corrección a la baja de los aumentos de precios y de alquileres en 2020 no impidió que en dicho año dichas magnitudes registrasen aumentos ligeros, pero superiores a los de los salarios. En el periodo comprendido entre 2013 y 2020 los aumentos acumulados de los precios de los alquileres fue el $56,9 \%$, el de los precios de las viviendas alcanzó el 33,8\%, mientras que los salarios por persona ocupada, estimados por el 


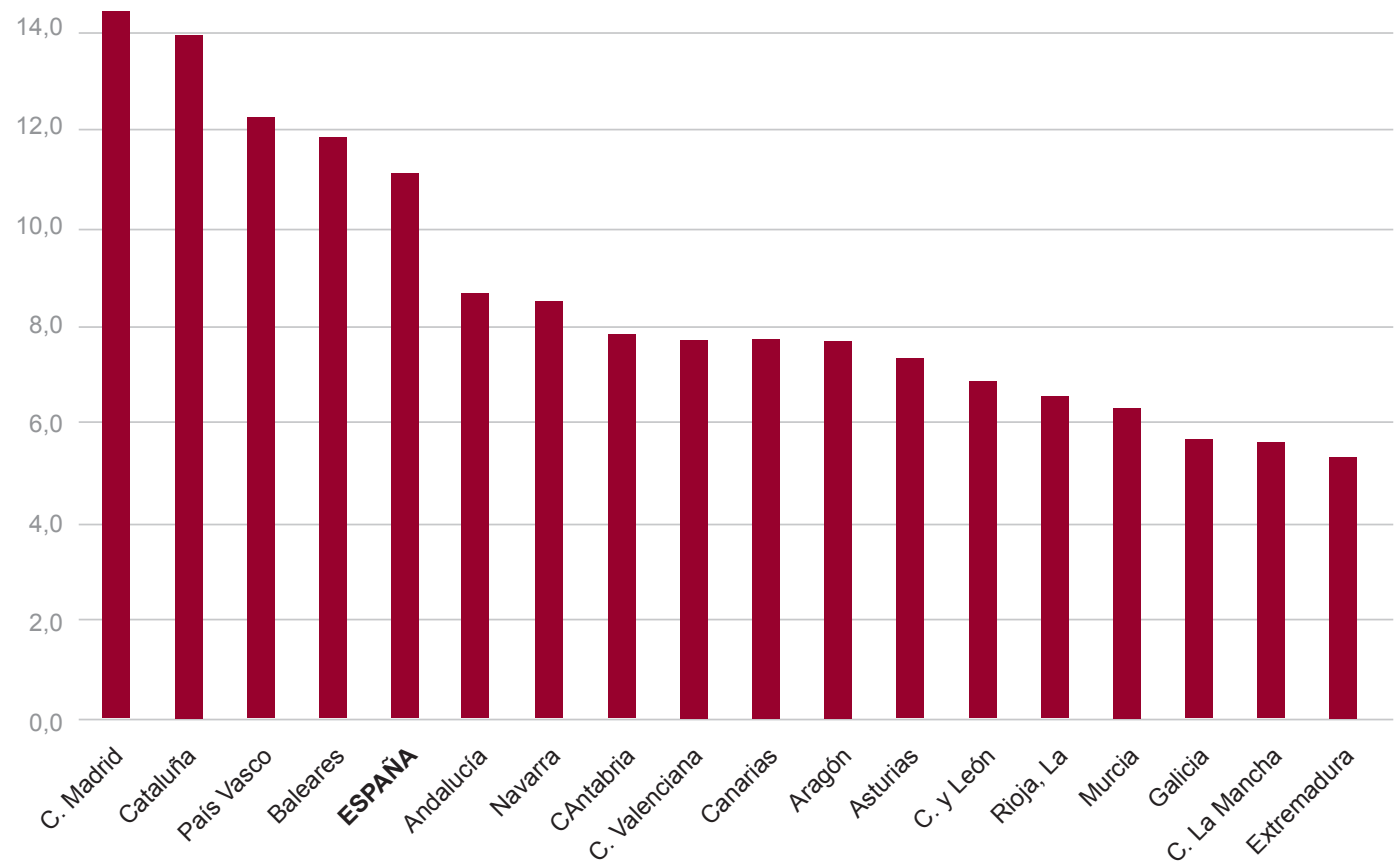

FIG. 9/ Alquileres. España y CC. Autónomas, euros/m²-mes. Datos de noviembre de 2020.

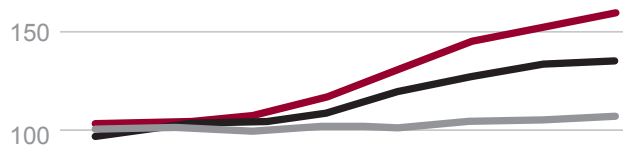

50

0 2013201420152016201720182019 2020*

- Precios Alquiler Salarios

Fig. 10/ Viviendas: Precios, alquileres y Salarios, $100=2013$. Datos anuales, 2013-2020 (previsión),

Fuente: INE e Idealista.com.

INE en su encuesta trimestral de salarios, fue solo el 3\% (FIG. 10). Dicha evolución conjunta de alquileres, precios de venta y salarios explican de forma clara las dificultades crecientes de acceso a la vivienda para los hogares, en especial para los de nueva creación.

\section{Mercado de vivienda (II) Demanda, financiación, tipos de interés}

Como antes se indicó, la debilidad del crecimiento de la economía española en el último trimestre de 2020 no ha ayudado a la persistencia del crecimiento de las variables básicas del mercado de vivienda. 2020 va a ser, como tantos otros mercados y actividades, un año negativo para el mercado de vivienda, como consecuencia de los sucesivos brotes de la pandemia del coronavirus Covid 19.

La caída del empleo ha producido un descenso en la renta disponible de los hogares, lo que ha frenado las compras de vivienda. Así, pues, las compraventas de viviendas pueden descender en 2020 en un $20 \%$, el número de préstamos hipotecarios puede disminuir en un $16 \%$ y el consumo aparente de cemento retrocederá en más del $10 \%$. Crecerá la morosidad bancaria por el lado de los préstamos a comprador de vivienda. Los precios de venta de las viviendas y los alquileres registrarán ligeros descensos. 
El retroceso del empleo, visible en la evolución de los afiliados a la Seguridad Social, que descendió en un $2,3 \%$ entre noviembre de 2020 y el mismo mes del año anterior (FIG. 11), unido al descenso medio de los salarios registrado en el promedio de los tres primeros trimestres del año $(-5,2 \%)$, contribuyó a que retrocediera la renta disponible de los hogares en los tres primeros trimestres de 2020. Dicha circunstancia contribuyó a deprimir la demanda de vivienda en este año.

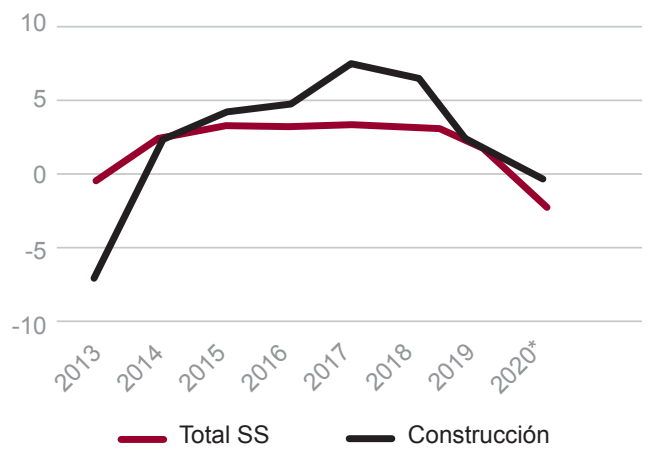

FIG. 11/ Afiliación a la Seguridad Social. Total afiliados y afiliados en el sector de la construcción. Tasas de variación interanuales, 2013-2020 (previsión) (\%).

Fuente: MinISTERIO de InCLUSIÓN Y dE LA SEgURIDAd SOCIAL.

El número de hipotecas formalizadas con garantía de una vivienda descendió en un 7,6\% en los nueve primeros meses de 2020 sobre el año anterior (FIG. 12). Dicho descenso fue más acusado en el número de préstamos hipotecarios destinados a la compra de vivienda, según la estadística notarial. Puesto que el descenso de las compraventas de viviendas fue superior al del número de hipotecas citado, la proporción de compras de viviendas financiadas con un préstamo hipotecario aumentó en 2020 , alcanzando dicha proporción un nivel del $84 \%$, muy superior al de los años anteriores (FIG. 13).

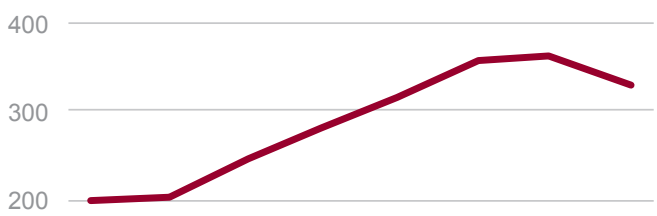

100

0

20132014201520162017201820192020

Número de hipotecas sobre viviendas (miles). Totales anuales, 2013-2020 (previsión).

Fuente: INE.

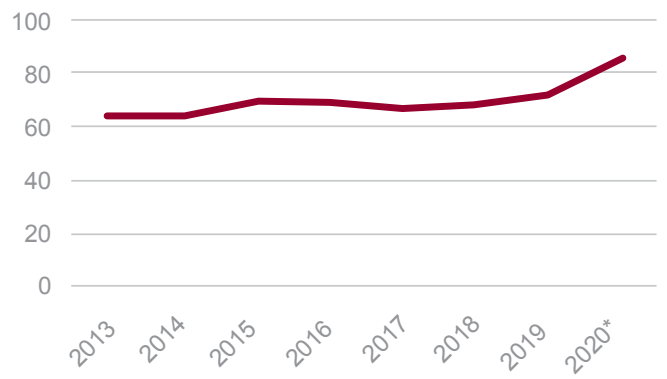

Proporción de hipotecas registradas sobre compraventas registradas de viviendas (\%). Datos anuales, 2013-2020 (previsión).

Fuente: INE.

En 2020 los tipos de interés de los préstamos a comprador de vivienda disminuyeron a un ritmo moderado a lo largo del año, situándose en noviembre en el 1,66\% (FIG. 14). El tipo de interés del índice de referencia de los préstamos hipotecarios para compra de vivienda, el Euribor a doce meses, descendió asimismo en los nueve primeros meses de 2020. El diferencial entre los tipos de interés de los préstamos y el Euribor creció ligeramente a lo largo de 2020, situándose en noviembre en el nivel de 2,14 puntos porcentuales.

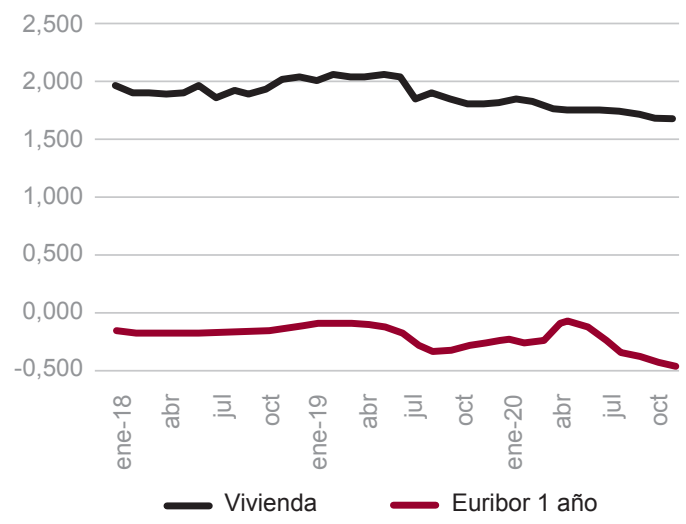

FiG. 14/ Tipos de interés de los préstamos a comprador de vivienda y euribor a 12 meses (\%). Datos mensuales, 2018-2020.

Fuente: BANCO DE España.

El volumen de nuevos préstamos a comprador de vivienda, estimado mediante encuesta por parte del Banco de España, descendió en un $3,3 \%$ en 2020 sobre el ejercicio precedente en el periodo enero-octubre, alcanzando un volumen previsiblemente superior a los 42.100 millones de euros en este año. El descenso fue mayor en el caso de las operaciones no renegociadas, que disminuyeron en un $6,9 \%$. 
La evolución de las dos magnitudes citadas implicó que en 2020 ha tenido lugar un fuerte aumento de las operaciones de crédito renegociadas. Dichas operaciones alcanzaron los niveles más elevados en los meses de mayo y junio, y en el periodo septiembre-octubre mantuvieron niveles muy superiores a los correspondientes a los cuatro primeros meses del año (FIG. 15). Esta evolución revela la presencia de dificultades para hacer frente a las cuotas de los préstamos a comprador de vivienda, como consecuencia del descenso registrado en los niveles de actividad y empleo en los meses correspondientes a la "primera ola" de la pandemia.

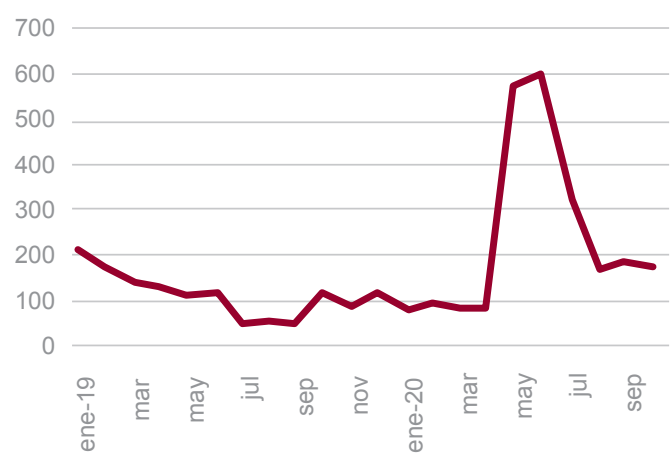

Créditos a comprador de vivienda,

operaciones renegociadas, millones de euros.

Datos mensuales, 2019-2020.

Fuente: BANCo de EsPaña

Según datos procedentes de los registros de la propiedad publicados por el INE, las compraventas de viviendas disminuyeron en un $21,2 \%$ en el periodo enero-octubre de 2020 sobre el año precedente. El nivel previsible de compraventas para 2020 puede estar por debajo de las 400.000 compraventas, unas cien mil viviendas menos vendidas que en 2019, año en el que el volumen de ventas ascendió a 501.086 (FIG. 16). El descenso fue más acusado en las ventas de viviendas de segunda mano, que retrocedieron en un $22,8 \%$ sobre el año precedente, mientras que el retroceso de las ventas de viviendas de nueva construcción fue el $14,3 \%$.

El descenso de las compraventas de viviendas estimado en la estadística de los notarios fue el $19,5 \%$ en el periodo enero-octubre de 2020 . El número de préstamos hipotecarios destinados a la compra de una vivienda disminuyó en un $13,9 \%$ en el periodo citado. En la información estadística publicada por el Consejo General del Notariado destaca la cifra correspondiente a las ventas mensuales de viviendas corregidas de estacionalidad. A la vista del perfil mensual de dichas ventas en 2020 (FIG. 17) se deduce

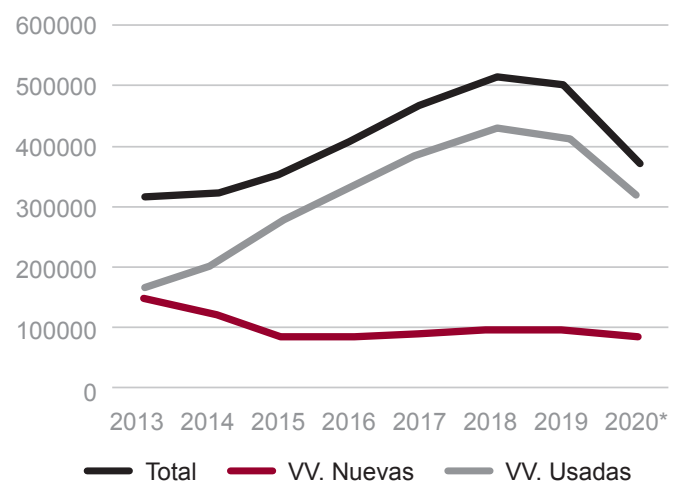

FIG. 16/Compraventas registradas de viviendas. Totales anuales, 2013-2020 (previsión), viviendas nuevas y usadas.

Fuente: INE.

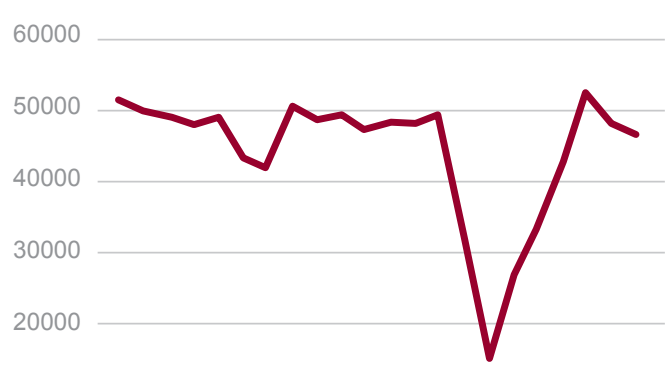

10000

0

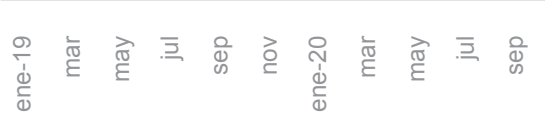

17/ Compraventas de viviendas, Serie mensual, 2019-2020, corregida de variación estacional.

Fuente: Estadística Registral, Consejo General del Notariado.

que dichas ventas registraron disminuciones destacadas entre los meses de marzo y junio de este ejercicio. La recuperación de las ventas fue importante en el tercer trimestre de 2020, desacelerándose la recuperación en octubre.

\section{Mercado de vivienda (III). La nueva oferta}

Las viviendas iniciadas, estimadas mediante los visados de obra nueva emitidos por los Colegios de Arquitectos Técnicos, descendieron en un $17,5 \%$ en los nueve primeros meses de 2020. La previsión para 2020 es de un total de iniciaciones que puede estar por debajo de las 90.000 (106.300 fue el total correspondiente a 2019) (FIG. 18). 


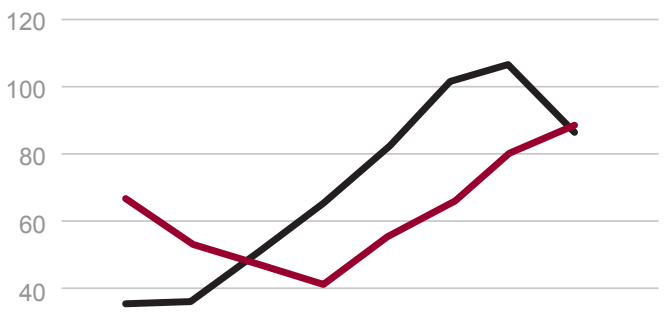

20

0

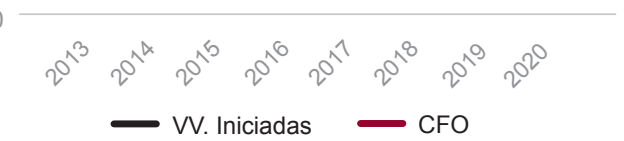

Viviendas. Visados de obra nueva y certificados de fin de obra (CFO). Datos anuales, 2013-2020 (previsión).

Fuente: $M^{\circ}$ DE Transportes, MoviLidad y Agenda URbana.

Las viviendas terminadas, estimadas a partir de los certificados de fin de obra emitidos asimismo por los Colegios de Arquitectos Técnicos, crecieron en un $10,9 \%$ en el periodo correspondiente a los tres primeros trimestres de 2020.La previsión para 2020 es de un total de viviendas terminadas de 87.400 .

Las nuevas viviendas construidas después de la crisis de 2008-11 han evolucionado en unos niveles reducidos si se comparan los totales anuales del periodo 2013-2019 con las construcciones previas a la etapa de la "burbuja" inmobiliaria. En las compraventas de viviendas registradas ha habido un fuerte predominio de las ventas de viviendas usadas frente a las de nueva construcción. Esta últimas han destacado en 2020 por el sensible mayor aumento de los precios de venta, el $7,5 \%$ anual en el tercer trimestre de 2020 , frente al $1,7 \%$ de aumento de los precios del conjunto de las viviendas.

A pesar del aumento experimentado por las viviendas terminadas en 2020 , los niveles alcanzados por dicha magnitud en el periodo de recuperación comprendido entre 2013 y 2019 han sido también muy inferiores a los correspondientes a la etapa pre-burbuja. En 2020 ha sido importante el aumento de las viviendas terminadas promovidaspor cooperativas, mientras que ha descendió ligeramente el número de viviendas terminadas promovidas por las administraciones públicas.

La previsión para 2020 es de un total de viviendas terminadas de 87.400 , de los que 4.165 habrían sido promovidas por cooperativas y unas 480 lo habrían sido por las administraciones públicas. El conjunto de viviendas promovidas por

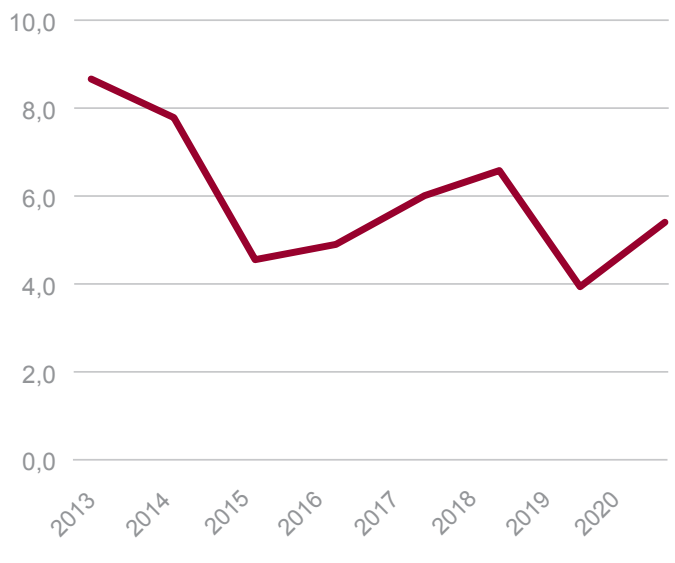

Viviendas terminadas. Proporción de viviendas construidas por cooperativas y por administraciones públicas (\%). Datos anuales, 2013-2020 (previsión).

Fuente: MITMA.

cooperativas y administraciones públicas podría suponer en 2020 el 5,3\% del total de viviendas terminadas, proporción reducida pero superior a la del año precedente (FIG.19).

En la etapa de recuperación del mercado de vivienda comprendida entre 2013 y 2019 las ventas de viviendas de nueva construcción han superado ampliamente a las viviendas nuevas terminadas. Ello puede implicar que en el periodo citado de recuperación de la demanda se ha dado salida a una parte importante del amplio stock de viviendas terminadas y no vendidas que existía al término de la fase de recesión posterior a la "burbuja". En 2020 las viviendas terminadas pueden superar por primera vez desde 2012 al número de ventas de viviendas de nueva construcción (FIG. 20).

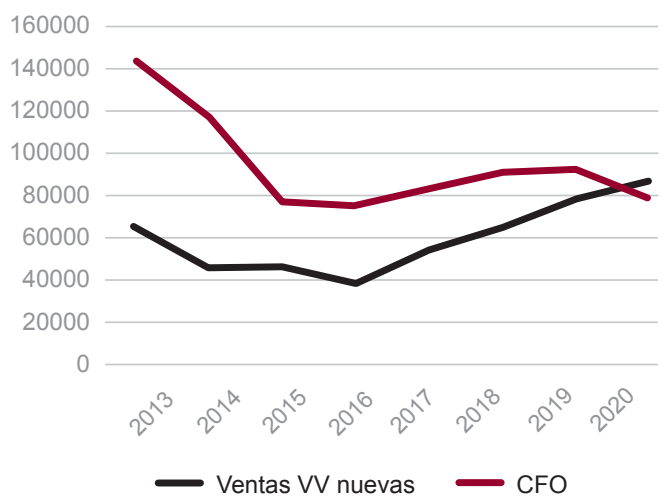

FIG. 20/Viviendas terminadas (CFO) y ventas de viviendas de nueva construcción. totales anuales, 2013-2020 (Previsión).

Fuente: INE y MITMA. 


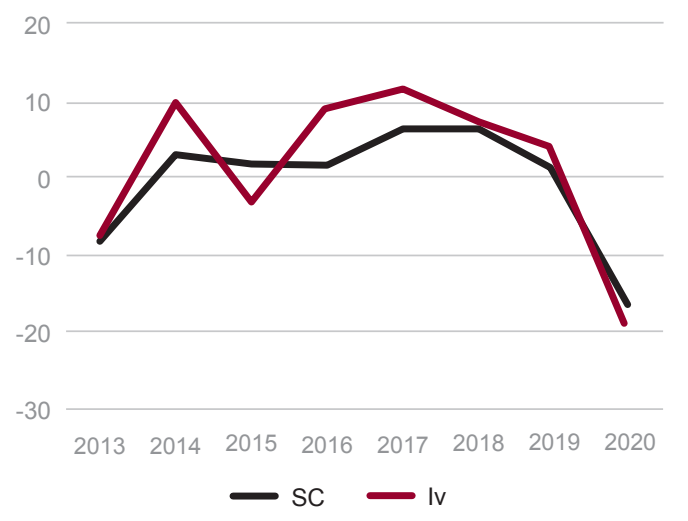

FIG. 21/ Vivienda y sector de la construcción. Tasas de variación interanual, precios constantes, 2013-2020 (previsión).

Fuente: INE.

Como consecuencia de la pandemia y de los confinamientos derivados de la misma, el sector de la construcción ha sufrido un descenso importante en los tres primeros trimestres de 2020. Según la Contabilidad Nacional Trimestral, en los tres primeros trimestres de 2020 el retroceso del sector de la construcción por el lado de la demanda ha alcanzado un ritmo del $-16,6 \%$, resultando superado dicho descenso por el subsector de la vivienda (-19,3\%). En este último el prolongado confinamiento ha impedido un mayor ritmo de nueva construcción y de iniciaciones de nuevas viviendas (FIG. 21).

\section{Política de vivienda}

En 2020 las ventas de Viviendas de Protección Oficial (VPO) han descendido a un ritmo superior al del conjunto de las ventas. En los diez primeros meses de este ejercicio dichas ventas retrocedieron en un $25,4 \%$, con lo que la previsión de ventas para 2020 se aproximará a un total de 35.500 VPO (FIG. 22). La mayoría de dichas ventas debe corresponder a viviendas protegidas usadas. Dicho total supone un $9,5 \%$ del total de ventas de viviendas en España previsto para 2020. La proporción resultó interior a la de 2019 (9,5\%).

En los tres primeros trimestres de 2020 el total de lanzamientos judiciales practicados en España descendió en un $53 \%$ sobre el año anterior. Dicha evolución no recoge las moratorias practicadas, que afectaron sobre todo al componente de lanzamientos asociados con el impago de alquileres. El retroceso de los lanzamientos asociados con los alquileres fue de un $51,8 \%$, mientras que en el caso de los lanzamientos asociados con el impago de un préstamo hipotecario la disminución fue de un 40,2\% (FIG. 23).

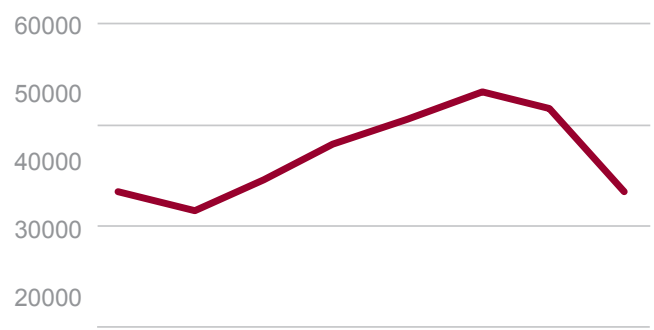

10000

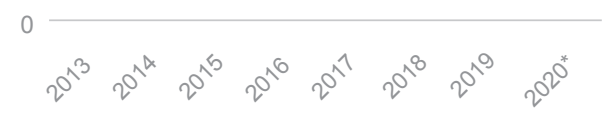

Compraventas de VPO. Número de viviendas, totales anuales, 2013-2020 (previsión).

Fuente: INE.

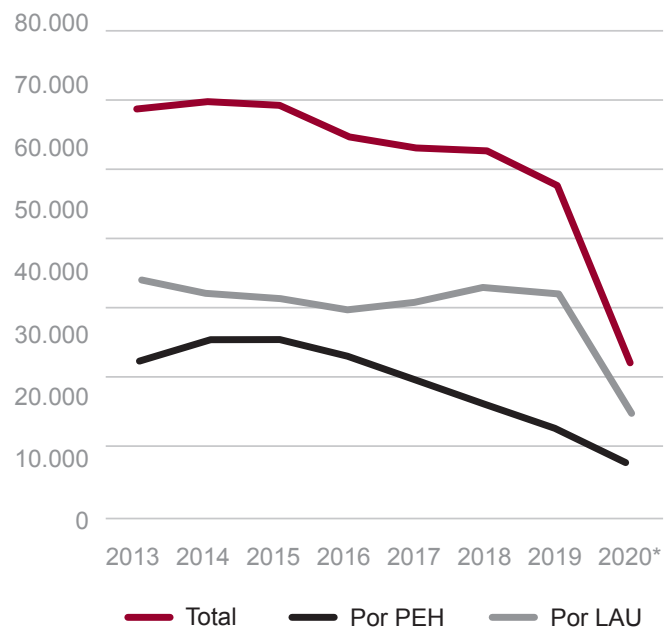

FIG. 23/ Lanzamientos judiciales practicados.

Total, por ejecución hipotecaria y por aplicación LAU. Datos anuales, 2013-2020 (previsión).

Fuente: Consejo General del Poder Judicial.

Los datos trimestrales revelan que el descenso de los lanzamientos tuvo lugar sobre todo en el segundo trimestre de 2020, periodo en el que fue mayor la incidencia de la pandemia, aunque los niveles del tercer trimestre también estuvieron por debajo de los del mismo periodo de 2019.

No se dispone de datos correspondientes al conjunto de 2020. Los datos disponibles por Comunidades Autónomas para 2019, revelan que, en materia de lanzamientos por impago del contrato de alquiler, de un total anual de 36.467 correspondió a Cataluña el nivel más elevado anual (8.427 lanzamientos), seguida de Andalucía (5.135) y Madrid (4.849) (FIG. 24). 


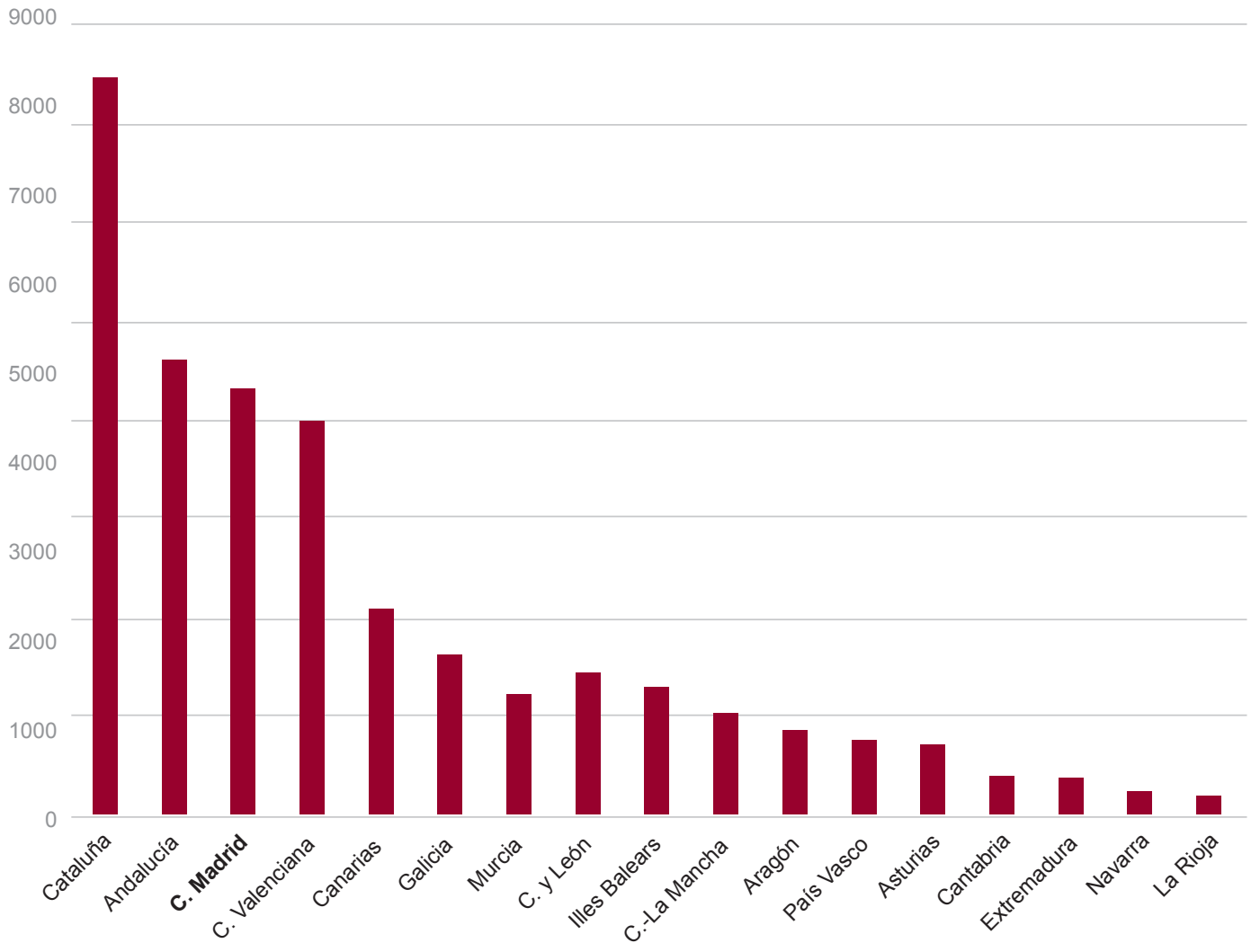

4/ Lanzamientos judiciales por impago de alquileres (LAU). Totales anuales en 2019.

Fuente: Consejo General del Poder Judicial.

En cuanto a los lanzamientos derivados de la ejecución de préstamos hipotecarios, de un total de 14.193 lanzamientos en 2019, fue Andalucía la autonomía con más desahucios de dicho tipo (3.117), seguida por la Comunidad Valenciana (2.633). Navarra y La Rioja aparecen en los últimos puestos en materia de lanzamientos judiciales, tanto en los ligados al cumplimiento de la ley de arrendamientos urbanos (LAU) como en los derivados de un préstamo hipotecario impagado.

El contenido del Proyecto de Presupuestos Generales del Estado para 2021 (PGE 2021) correspondiente a Vivienda implica un crecimiento significativo en el conjunto de las ayudas al gasto en vivienda y en el importe de las desgravaciones fiscales incluidas respecto del Proyecto de Presupuestos para 2018. Una parte de los gastos previstos se va a financiar con recursos procedentes del instrumento Next Generation EU. Se está todavía lejos de los niveles relativos de ayudas a la vivienda de hace más de diez años. Sin embargo, por primera vez en bastante tiempo hay un repunte de cierto alcance en la dimensión de las ayudas previstas para el acceso a la vivienda.
El gasto público directo destinado a la Vivienda asciende a 2.253 millones de euros en los PGE 2021 (474 millones en 2018). Dentro de dicha partida hay 72,0 millones de euros destinados a pagar subvenciones de intereses de planes precedentes. Esta partida tiene un lógico carácter decreciente. Dentro del apartado de gasto, 354 millones se destinarán a subvencionar el vigente Plan de Vivienda 2018-21. En dicho plan se incluyen sobre todo ayudas a los inquilinos para pagar el alquiler y subvenciones a la construcción de viviendas sociales.

En cuanto a las ayudas al alquiler, podrán desde 2021 subsidiar a alquileres de hasta 900 euros mensuales, mientras que hasta ahora el tope era de alquileres de hasta 600 euros al mes. Se conoce poco acerca de las viviendas sociales construidas por medio de las ayudas previstas en el vigente Plan Estatal de Vivienda 2018-21. El desconocimiento del destino de las partidas de gasto realizado a través de las autonomías impide valorar el alcance de las ayudas para la construcción de dicho tipo de viviendas. Airef señaló en su día que las partidas de gasto público 
peor conocidas en su destino final dentro de los presupuestos anuales estatales eran las ayudas a la vivienda concedidas a las autonomías.

Los PGE 2021 incluyen 100,4 millones de euros para el denominado Plan 20.000, que prevé la construcción del mismo número de viviendas sociales destinadas al alquiler. Dichas viviendas se construirían en solares pertenecientes hasta ahora al organismo SEPES, donde se incluyen los situados en la zona de los antiguos cuarteles del ejército en Madrid. El Ministerio de Transportes, Movilidad y Agenda Urbana no específica qué carácter tendrían dichas viviendas, si serian viviendas protegidas o viviendas libres con posibilidades o no de reventa rápida.

La novedad del Plan es la partida de gasto correspondiente a "Rehabilitación para la recuperación económica y social a través de las comunidades autónomas". Dicha partida asciende a 1.550,6 millones de euros y cubre actuaciones de rehabilitación que desarrollarían las comunidades autónomas y que el gobierno estatal subvencionaría con recursos procedentes de la Unión Europea. La rehabilitación de viviendas tiene buena prensa en España, está bien vista por todas las fuerzas políticas, pero el escaso parque de viviendas sociales existente solo aumenta si se rehabilitan viviendas vacías.

En las viviendas ocupadas, con la rehabilitación se mejora la calidad de vida de los ocupantes, pero no aumenta, pues, con ello la oferta de viviendas de alquiler. El gobierno hace una seria apuesta por la rehabilitación financiada mediante transferencias a las autonomías. Sin embargo, en los presupuestos no se introducen partidas de gastos significativas como para inducir un aumento importante del exiguo parque disponible de viviendas sociales de alquiler.

Las ayudas fiscales al acceso a la vivienda se aproximan a 2.700 millones de euros (2.172 en los PGE de 2018). Dentro de dicha partida destaca el alcance de las partidas destinadas a desgravar fiscalmente el acceso a la vivienda. El primer componente de la partida total antes citada es el relativo a la deducción en la cuota del IRPF a los compradores de vivienda habitual, cuya cuantía se eleva a unos 940 millones de euros y que está suprimida para nuevos adquirentes desde 2013. De momento disfrutan dicha deducción en la cuota del IRPF unos tres millones de contribuyentes. La deducción en la cuota a los inquilinos por alquiler de la vivienda habitual asciende a 41,5 millones de euros, también en régimen transitorio tras la supresión de dicha figura por parte del gobierno popular. La deducción citada la disfruta un total de 213.709 contribuyentes.

La segunda deducción fiscal más relevante es la que obtienen los particulares que destinan viviendas al alquiler. El importe total de las deducciones se eleva a 671,2 millones de euros en 2021, correspondientes a reducciones en la base imponible del IRPF. Dicha reducción la disfruta un total de casi dos millones de contribuyentes. Están exentas del IRPF las ganancias patrimoniales obtenidas en la venta de una vivienda si se destinan a la compra de otra vivienda habitual. El alcance de las exenciones asciende a 340 millones de euros y la obtuvieron en 2019 un total de 61.850 contribuyentes. Las ganancias patrimoniales obtenidas por los mayores de 65 años por la venta de la vivienda habitual también están exentas en el IRPF, previéndose una exención en 2021 de 65 millones de euros por este concepto, disfrutada por un total de 7.841 contribuyentes.

Las entidades dedicadas al arrendamiento de viviendas obtienen una bonificación en la cuota íntegra del impuesto sobre sociedades prevista para 2021 de 48 millones de euros, disfrutada por 1.250 contribuyentes. Por último, la aplicación de un tipo impositivo del $10 \%$ en el IVA aplicado a la venta de viviendas de nueva construcción implica un tipo reducido de dicho tributo, ascendiendo el beneficio fiscal a 585,9 millones de euros.

El conjunto de las ayudas a la vivienda en forma de gasto (2.253 millones de euros) y de ayudas fiscales (2.697 millones de euros), 4.950 millones de euros, equivalen al $0,45 \%$ del PIB de la economía española previsto para el próximo año en los PGE 2021. Dicha proporción está entre las más reducidas en los países de la Unión Europea $(0,6 \%$ del PIB).

Los PGE 2021 introducen, pues, algunas modificaciones sensibles en materia de política de vivienda, en especial dentro del componente del gasto destinado a la ayuda al acceso a la vivienda. Parce conveniente, sin embargo, un mayor crecimiento en las partidas destinadas a favorecer un aumento significativo en el parque total de viviendas sociales de España, uno de los más reducidos de Europa.

El Real Decreto 1084/2020, de 9 de diciembre (BOE de 10.12.2020) ha modificado toda la normativa existente en materia de programas incluidos en el Plan 2018-21. Destaca sobre todo la extensión del plazo de las ayudas contempladas en dicho Plan hasta el 31 de diciembre de 2022. Entre otras medidas, se amplía el plazo de ejecución de las actuaciones de fomento del parque público de vivienda en alquiler y fomento de la regeneración y renovación urbanas, articuladas al amparo del Plan Estatal 2013-16 y su prórroga, en dos años, hasta el 31.12.2022.

El Consejo de Ministros de 22.12.2020 aprobó un nuevo Real Decreto-ley de medidas urgentes 
para hacer frente a las situaciones de vulnerabilidad social y económica en el ámbito de la vivienda, el Real Decreto-ley 37 /2020, de 22 de diciembre (BOE de 23.12.2020). Para asegurar la protección de las personas arrendatarias de vivienda en situación de vulnerabilidad, se amplía el alcance temporal y subjetivo de las medidas establecidas para responder a la gravedad de las consecuencias de la pandemia.

En este sentido destaca la extensión hasta la finalización del estado de alarma de la posibilidad de suspensión del procedimiento de desahucio. La suspensión del lanzamiento se mantendrá por el tiempo necesario para aplicar las medidas sociales que procedan, siempre dentro del periodo del estado de alarma (RD 956/2020, de 3 de noviembre).

En el contexto del estado de alarma se ofrece especial protección a aquellos hogares afectados por procedimientos de lanzamiento de su vivienda habitual, que no se deriven de contratos de arrendamiento, cuando existan personas dependientes, víctimas de violencia sobre la mujer o menores de edad a su cargo. En la nueva norma se prevé que las comunidades autónomas podrán emplear los recursos del Plan Estatal de Vivienda 2018-21, regulado por RD 106/2018, a fin de hacer frente a las compensaciones previstas.

\section{Bibliografía}

FMI (2020): Economic Outlook, octubre.

OCDE (2020): Economic Outlook, diciembre.

TORRES, Raymond (2020): "El binomio Estado-mercado". El País de los Negocios, 20 de diciembre.

Touze, Adan (2020): "Talk of a global economic reset must no ignore grim realities". The Financial Times, diciembre. 